11. Zhang Y, Fu F, Hu H, Wang S, Li Y, Hu H, et al. Gefitinib as neoadjuvant therapy for resectable stage II-IIIA non-small cell lung cancer: a phase II study. J Thorac Cardiovasc Surg. 2021;161:434-42.e2.

12. O'Kane GM, Liu G, Stockley TL, Shabir M, Zhang T, Law JH, et al. The presence and variant allele fraction of EGFR mutations in ctDNA and development of resistance. Lung Cancer. 2019;131:86-9.
13. Del Re M, Rofi E, Cappelli C, Puppo G, Crucitta S, Valeggi S, et al. The increase in activating EGFR mutation in plasma is an early biomarker to monitor response to osimertinib: a case report. BMC Cancer. 2019;19:410.

14. NSCLC Meta-analysis Collaborative Group. Preoperative chemotherapy for non-small-cell lung cancer: a systematic review and meta-analysis of individual participant data. Lancet. 2014;383:1561-71.

\section{Commentary: Durable activity of a tyrosine kinase inhibitor in lung cancer}

\author{
Chadrick E. Denlinger, MD
}

Lung cancer treatment has progressed dramatically in the past decade with the emergence of tyrosine kinase inhibitors (TKI) targeting specific growth factor receptors and immune checkpoint inhibitors. After identifying that growth factor mutations, rather than simple overexpression, was a critical factor for the efficacy of TKIs, some of these agents became the preferred treatment for lung cancers. Epithelial growth factor receptor (EGFR) inhibitors, such as gefitinib and other newer agents, have replaced cytotoxic agents as the principal treatment for advanced-stage lung cancers for patients with activating mutations of EGFR based on improved efficacy and better side effect profiles. ${ }^{1}$ TKIs have a substantial influence on progression-free survival while overall survival rates remain similar to standard cytotoxic chemotherapy. ${ }^{2}$ It is well understood that the long-term treatment efficacy of TKIs is limited by cancers developing new point mutations or alternative escape pathways leading to TKI resistance and cancer progression. ${ }^{3}$ For this reason, TKIs are not currently indicated in any curative-intent treatment strategies.

Zhang and colleagues ${ }^{4}$ pushed the envelope to determine the efficacy of using gefitinib as neoadjuvant therapy followed by surgical resection of locally advanced lung cancer

From the Division of Cardiothoracic Surgery, Department of Surgery, Medical University of South Carolina, Charleston, SC.

Disclosures: The author reported no conflicts of interest.

The Journal policy requires editors and reviewers to disclose conflicts of interest and to decline handling or reviewing manuscripts for which they may have a conflict of interest. The editors and reviewers of this article have no conflicts of interest.

Received for publication April 8, 2020; accepted for publication April 8, 2020; available ahead of print April 23, 2020.

Address for reprints: Chadrick E. Denlinger, MD, Division of Cardiothoracic Surgery, Department of Surgery, Medical University of South Carolina, 114 Doughty St, Charleston, SC 29425 (E-mail: denlinge@musc.edu).

J Thorac Cardiovasc Surg 2021;161:446-7

$0022-5223 / \$ 36.00$

Copyright (c) 2020 by The American Association for Thoracic Surgery

http://dx.doi.org/10.1016/j.jtcvs.2020.04.042
Check for updates

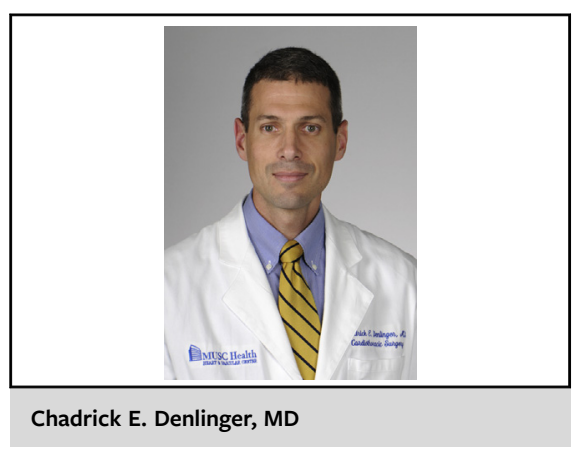

CENTRAL MESSAGE

Surgery for locally advanced lung cancers following neoadjuvant gefitinib appears safe with surprisingly optimistic long-term outcomes.

harboring EGFR activating mutations. ${ }^{4}$ Most importantly, the treatment protocol appears safe with short-term surgical outcomes that were comparable to other neoadjuvant treatment protocols. Indeed, there were no 90-day mortalities and the median operative blood loss was $100 \mathrm{~mL}$. Loose correlations between clinical response and pathological response open the door for interpretation. However, the direct relationship between pathological response and both progression-free and overall survival are logical and correlate with well-established outcomes associated with neoadjuvant treatments. ${ }^{5}$

The overall survival rate of $66 \%$ is quite impressive for a cohort of stage II through IIIA patients even when considering that some reports suggest lung cancer patients with mutant EGFR have improved outcomes relative to EGFR wild-type patients. ${ }^{6}$ This is particularly true when considering that 27 of 33 patients included in the survival analysis were diagnosed with stage IIIA disease. One concern for the unusually favorable results is the potential for selection bias, and this concern is accentuated by the exclusion in 
the outcomes analysis of 2 patients who received neoadjuvant gefitinib but did not receive the entire treatment course or refused surgery. Another concern, as previous mentioned, is that under normal circumstances, TKIs typically remains efficacious for 12 to 18 months before tumors develop resistance mechanisms. Therefore, the prolonged survival among a cohort of patients with locally advanced disease is surprising. For these reasons, I agree with the authors' conclusions that TKIs should be further evaluated prospectively in neoadjuvant settings.

\section{References}

1. Mok TS, Wu YL, Thongprasert S, Yang CH, Chu DT, Saijo N, et al. Gefitinib or carboplatin-paclitaxel in pulmonary adenocarcinoma. N Engl J Med. 2009;361:947-57.
2. Morita S, Okamoto I, Kunihiko K, Kobayashi K, Yamazaki K, Asahina H, et al. Combined survival analysis of prospective clinical trials of gefitinib for non-small cell lung cancer with EGFR mutations. Clin Cancer Res. 2009; $15: 4493-8$.

3. Stewart EL, Tan SZ, Liu G, Tsao MS. Known and putative mechanisms of resistance to EGFR targeted therapies in NSCLC patients with EGFR mutations-a review. Transl Lung Cancer Res. 2015;4:67-81.

4. Zhang Y, Fu F, Hu H, Wang S, Li Y, Hu H, et al. Gefitinib as neoadjuvant therapy for resectable stage II-IIIA non-small cell lung cancer: a phase II study. J Thorac Cardiovasc Surg. 2021;161:434-42.e2.

5. Kwong KF, Edelman MJ, Suntharalingam M, Cooper LB, Gamliel Z, Burrows W, et al. High-dose radiotherapy in trimodality treatment of Pancoast tumors results in high pathologic complete response rates and excellent long-term survival. J Thorac Cardiovasc Surg. 2005;129: 1250-7.

6. Marks JL, Broderick S, Zhou Q, Chitale D, Li AR, Zakowski MF, et al. Prognostic and therapeutic implications for EGFR and KRAS mutations in resected lung adenocarcinomas. J Thorac Oncol. 2008;3:111-6. 